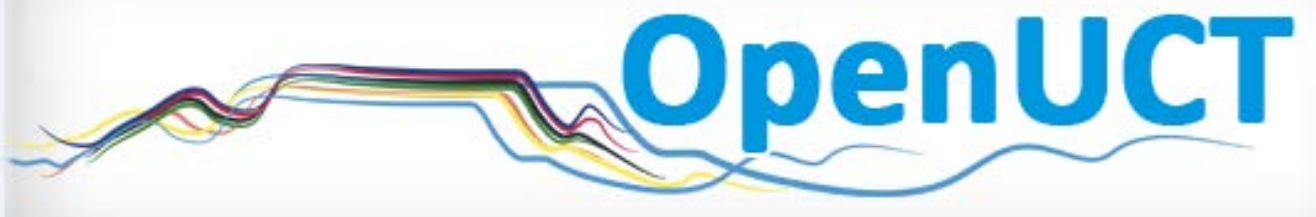

This is the post-print of Archer, A. 2011. Clip-art or design: Exploring the challenges of multimodal texts for writing centres in higher education. Southern African Linguistics and Applied Language Studies. 29(4): 387-399. DOI: 10.2989/16073614.2011.651938.

It is made available according to the terms of agreement between the author and the journal, and in accordance with UCT's open access policy available:

http://www.openuct.uct.ac.za/sites/default/files/UCTOpenAccessPolicy.pdf, for the purposes of research, teaching and private study. 
Title of paper: $\quad$ Clip-art or Design: Exploring the challenges of multimodal texts for Writing Centres in Higher Education

Name of author: $\quad$ Dr Arlene Archer

Institution: University of Cape Town

Mailing address: Writing Centre

Academic Development Programme

Centre for Higher Education Development

Hlanganani Building

University of Cape Town

Private Bag

Rondebosch, 7700

South Africa

Telephone: $\quad$ +27216503319(w)

+27216856243(h)

Fax: $\quad+27216505045$

E-mail: $\quad$ Arlene.Archer@uct.ac.za 


\title{
Clip-art or Design: Exploring the challenges of multimodal texts for Writing
}

\section{Centres in Higher Education}

\begin{abstract}
In Higher Education, genre theorists and academic literacy practitioners have examined evolving genres, but they have not specifically focused on the multimodal nature of texts that students need to produce for assessment purposes. This paper explores the increasing influence and incorporation of the visual into academic texts, and ways of enabling student access to academic discourse in a multimodal environment. Taking a multimodal perspective on 'academic literacies', it looks at examples from different disciplines and provides guidelines on how Writing Centres can assist students with the designs of their multimodal texts in a changing representational landscape. In particular, it focuses on helping students with predominantly visual texts, integrating visuals into written assignments, and ways of writing about images.
\end{abstract}

\section{Key words}

Academic literacies, social semiotics, multimodal texts, Writing Centres, access 


\section{Introduction}

The teaching of writing and academic literacy practices in Higher Education is inextricably linked to student access, which includes both retention and throughput (see Archer 2008). Lea and Street (1998) show how joining the academy can be problematic for those trying to learn its rules of entry from non-dominant or disadvantaged positions in the power structures of Higher Education and the society in which it is embedded. Writing Centres are well-placed to play a vital role in this equity redress. However, there has tended to be an overemphasis on the teaching and analysis of writing in academic literacy practices (Archer 2006). Although this emphasis has been placed on writing for sound pedagogical reasons, Kress and Van Leeuwen (2006), Kress (2000a; 2000b), Stein (2008), NLG (2000) and others have pointed to the overemphasis on logocentricism, the significance of 'writing' as a mode, often to the neglect of other modes and their interconnectedness. By mode, I mean a fully semiotically articulated means of representation and communication, such as language, image or music.

Students' assignments require increasingly complex multimodal competencies and Writing Centres need to be equipped to help students with the construction of these texts. Many assignments use visuals as evidence in disciplines such as anthropology and history, whilst some assignments are predominantly visual in nature, such as posters, or assignments that include CD roms or other media. As with predominantly written assignments, multimodal texts raise issues about power and access in Higher Education. Thesen (2001) argues that analysis of multimodal texts in the Humanities requires students to engage with different levels of language: English, academic discourse, mode-specific language associated with the analysis of the visual and a metalanguage of critical analysis. This can be extremely complex, both for the students as well as the consultants in the Writing Centre. Composing multimodal texts is also not a simple process. Composing is not just about selecting multimodal semiotic resources, but it is also about the weight given to each mode in a particular text. Often students write their own text, but copy and paste the pictures. This prioritizes the written mode and the visual gets relegated to the status of 'decoration'. The increasing use of images in assignments requires us to use sources differently. Images are sometimes used to 'pad' essays, to make them longer or seemingly more 
scientific, are often used inappropriately or vaguely and not integrated into the argument.

An important reason for the emergence of some new multimodal genres in academia is the rise of new technologies. New technologies of writing enable a range of possibilities for individuals creating documents, including layout, image, colour, typeface, sound. According to Luke, in a "symbol saturated environment", it is important to be able to "construct, control, and manipulate visual texts and symbols" (quoted in Jewitt 2006: 9). The challenge for Writing Centres is both to utilize new technologies effectively and to remain equipped to deal with the changing nature of assignments as a result of them. We need to analyze the new processes of production and creativity in the new media. How different, for instance, is the process of learning in copying and pasting, as opposed to drawing something yourself? Images taken from 'clip-art' are not necessarily pre-coded, but become a new sign in the way that they are used in the 'interest' (Kress 2010) of the designer.

This paper takes a multimodal perspective (Kress 2010, Jewitt 2009) to re-look at the key concerns of an 'academic literacies' approach to teaching writing (Lillis and Scott 2007). Broadly speaking, an academic literacies approach focuses on student identity, institutional relationships of discourse and power, and the contested nature of writing practices. According to this view, a feature of academic literacy practices is "the requirement to switch practices between one setting and another, to deploy a repertoire of linguistic practices appropriate to each setting, and to handle the social meanings and identities that each evokes” (Lea and Street 1998:159). Crucial to this approach is a concern with agency and power and how to provide diverse students access to academic practices in ways that utilize and value their resources. The norms and conventions around constructing multimodal texts in Higher Education are no more 'transparent' than the norms around writing. It is thus important to look at texts in Higher Education that require engagement with and integration of images. The texts examined here are chosen as exemplars of three types of multimodal assignments encountered in a Writing Centre at a particular South African university. These three types include predominantly visual texts, written texts that use images, and written texts that analyze and discuss visuals. Predominantly visual texts accompanied by written reflection include posters, power point presentations, 
websites, storyboards, written text together with video or DVDs (often at postgraduate level when the data is displayed in this way). Predominantly written assignments use images to illustrate a point, as evidence, as argument, or for other rhetorical purposes. Examples of these are visual comparisons (as in Architecture), use of an image to provide context such as in Historical Studies or Linguistics, incorporation of tables and flowcharts. Lastly, there are a range of predominantly written texts that analyze and discuss visuals, for instance, analyses of films and advertisements in cultural studies, buildings in architecture, textbooks in education. See table 1 below for a characterization of these three categories of texts.

This paper looks at ways in which Writing Centre consultants can help students with these different types of multimodal text. The theoretical basis for the analysis and suggested interventions is multimodal social semiotics. The assumption underpinning this approach is that meaning is made through the selection and configuration of modes in texts and through the interests of the sign-maker in a particular context (Jewitt 2009: 15). As the coordinator of a Writing Centre, I am interested in the ways in which multimodal student texts are constructed and the extent to which students internalize the often unconscious (multimodal) practices of the discipline. Making these practices explicit and visible is crucial in the teaching of writing. In this paper, I look at student texts, including posters, storyboards, essays using visuals and essays analyzing visuals from Film and Media and History and Theory of Architecture.

\section{Helping students with predominantly visual assignments}

Predominantly visual texts have been quite rare in academia, but are becoming more plentiful, probably due to the dominance of new technologies. These include posters, storyboards, technical drawings, powerpoint presentations, visual comparisons and 'culture jamming' of media texts such as advertisements. I will look at the features of some of the above texts and how writing consultants can assist students in producing them.

Posters are becoming an increasingly prevalent text type in Higher Education. Student engineers produce posters routinely in their later years of study, and subjects like sociology and anthropology capitalize on the visual affordances of posters. For instance, in a sociology assignment, students were required to take photographs of 
public spaces over an election period - focusing on how election posters have been placed in that space and how their distribution changes over time. They were required to produce a poster themselves for assessment purposes, using their own photographs, maps and other diagrams. This was to be accompanied by a written reflection.

Table 1. Types of multimodal texts in academia [ tables, pictures and figures provided on the last pages of this work]

As a student-produced text, a poster is not necessarily dependent on new computer technologies, although the expectation around increasingly 'produced' texts is becoming greater. Posters are a common means of presenting research findings in both the academic community and the workplace. Although posters are a key academic genre, they are often not yet valued as highly as written genres. Perhaps this is because posters are not always regarded as complete texts, and the producer is often needed to present the text orally. However, the status of the poster could also have something to do with the traditionally lesser valued visual mode in academia. The poster is about visual and spatial display. Therefore, the written mode also needs to function visually, and here the use of typography, emphasis and white space become crucial. As with predominantly written text, the poster needs to be coherent on both macro and micro levels. In terms of macro organization, most important is the appropriacy of the representation to a particular audience and the ways in which the text constructs that audience. The choice of fonts, typefaces, lettering systems or calligraphy are important in terms of size, shape, lightness, boldness, as is the medium of representation, namely use of pens, brushes, pencils, word processors to produce a particular meaning for a particular audience. The visual needs to be uncluttered, with a clear reading path with connections between the different sections. The words and images generally need to complement each other. In terms of micro organizational aspects, colour needs to be used thoughtfully and the choice of image is important for the message being conveyed (for instance, the use of a graph, table, cross-section diagram, simplified two-dimensional drawing, flow chart, image from an image bank, photograph, perspective drawing, realistic drawing). From a Writing Centre perspective, this structure is not too different from a written academic assignment. Most of what we deal with in writing consultations is the structuring of text at different levels. (See Appendix A for guidelines that can be used in poster design. 
These guidelines are intended to open up questions around design, rather than to be prescriptive.)

Another example of a predominantly visual genre that our Writing Centre often has to deal with is that of a storyboard in a first year film course. Part of the course is a computer-based component called 'Director's Cut' which allows students to apply their understandings of film theory and to edit their own short sequences (Deacon, Morrison, Stadler 2005). Students produce a storyboard by choosing images, and then providing details on setting, cinematography, shot action, sound, lighting, editing for each image. They also provide a written rationale for their design choices, drawing on the theory of the course. In academia, visual genres are often anchored in the written in this way. This is partly because of the valorization of the written mode in this context, but may also have something to do with the affordances of the written mode for critical reflection. To be able to do this written reflection competently, however, one needs mastery over the particular metalanguage required. In this case, the metalanguage comprises terms from film and film editing (like point of view, flashbacks, camera angle, voice over). Below in figure 1 is an example of a student assignment produced in this computer tutorial. It is not a conventional printed storyboard, as each image is in fact a short film clip.

Table 2. Storyboard for short film entitled 'Dolls and Diamonds' produced by a first year Film student[beblow]

This storyboard has the somewhat over the top title of 'Dolls and Diamonds' which points to the film noir genre, but in a somewhat parodic way. According to Buckingham et al (1995), when students produce media texts they often parody the dominant genres and conventions. The storyboard begins with the arrival of the private eye, Dick. He has come to interrogate the femme fatale about what happened in room 237. When she reverses his question, he has a flashback to the evening in question when he saw the femme fatale leaving room 237. The voice-over of Dick is characterized by a hard-talking private eye, using words like 'shiner', 'pigs', 'gut' and 'dame’. 
The focus of this paper is how to help students produce these kinds of assignments. Specifically, we need to think about the interactions between modes in a text like this (gesture, body language, character movement, dialogue, music) as well as cinematic considerations such as camera angle, camera movement, lighting, cuts. This assignment may not be produced in paper-based format for the consultation, and the Writing Centre consultant may have to consult on the screen, looking at the moving images in each film excerpt. A consultant would approach the assignment in a similar way to predominantly written texts. They would begin by asking prompting 'why' questions in order to get the student to talk about their choices - how and why they decided on shot duration, camera angle, and so on. The main focus would be on what genre of film this is, and how the type of shot and the register of the dialogue fit into this genre. In this particular storyboard, it would be useful to explore the coherence of the plot with the student as it becomes rather difficult to follow after Dick's flashback.

As a general principle, the consultant can point out how rhetorical relations are used in the development of sequences in storyboards, and this includes sequences of images and the intersemiotic relationships between writing and images. Images can expand (elaborate, extend or enhance) one another (Martinec and Salway 2005). So, for instance, one image sequence may be elaborated by another by zooming in or out, providing either more detail or more context. An extreme form of elaboration is achieved through a close-up. Extension may be represented by a pan, as when a landscape is represented cumulatively (Matthiessen 2007: 33). Looking at sequencing of images is not only relevant in storyboards, but in other predominantly visual texts such as film, comics (Huang and Archer 2011) and certain scientific process images as well.

\section{Integrating visuals in written essays}

More common than visual texts in academia are written texts that utilize images in a range of ways. Images are used in conjunction with the written mode to provide context, illustrate a point, make an argument, furnish evidence, organize data. There are also a range of academic genres that require the use of numerical graphical representations, such as needs analyses, impact assessments, cost benefit analyses. 
In a first year architecture course, the History and Theory of Architecture, students are required to compare the social, cultural, experiential and design characteristics of two buildings. The Writing Centre provides input on how best to write a comparative essay, providing input on the possible structure of the essay as well as on the more micro level of cohesion, namely, the kinds of linking words used in a contrastive analysis. In an essay of this nature, however, it is not sufficient to only discuss these aspects. Often these kinds of essays require students to provide visuals as both evidence and illustration of their points. We thus need to think about how to integrate the visual and the verbal in terms of proximity, relations between image and writing, the function of the image and the choice of image.

Captions are used to explain the image in terms of the key point being made in the overall argument and also to explain the inclusion of the image. However, the relations between image and writing can be quite complex. In providing guidance to students on these relations, input can be based on Barthes (1977). The main concept is that of 'anchorage', using the written text (usually in the form of a caption) to delimit the meaning of the image. The writing functions as a kind of specification as the words illuminate one of the possible meanings of the image. Another word-image relationship is that of extension, where writing and image form a complementary relationship and each mode contributes its own, distinct but semantically linked information. Looking at more complex classifications of visual-verbal linkages is beyond the scope of this paper (see Royce 2002, Unsworth 2006 and Martine and Salway 2005 for more in-depth classifications).

Figure 2. Extract from a first year architecture essay[below]

The caption here is a specification as the image points to an example of one 'type' of architecture. However, there is a slight disjuncture between the surrounding writing and the image here. The writing talks about Groot Constantia and the image is of the Tulbach Guest House. The image serves the function of filling the content gap in the written explanation between the description of Groot Constantia, and the statement that a definitive South African architectural language was born. It is as though using the image provides the ready-made explanation of the features of "typical Cape Dutch" architecture, namely the rounded gable, thatched roof, sash windows and 
whitewashed walls. This points to the functional specialization of the visual mode, where the image is more specific than the written text. So, the shape of the building has to be shown in the image, whereas it is not described in the writing. Kress (2003) calls this the 'epistemological commitment' of the mode. The positioning of “(fig. 2)" is important in the written text. If placed after "Van der Stel” then it would probably exemplify that statement, making the disjuncture between 'Groot Constantia' and 'Tulbach Guest House’ even larger. In its current position (after “A definitive South African architectural language was born”), it points to a 'type' of architecture, rather than a specific building.

Writers need to think about the function an image is performing in a text. Is the image serving as an illustration or is it being used as evidence in an argument? It is also important to evaluate the type of image that is chosen for a particular purpose. For instance, a sketch might emphasize certain structural aspects of a building such as symmetry, whereas a more schematic diagram would better represent some of the technicalities of design. See Archer (2011) for an exploration of the ways in which academic voice operates across image and writing in a History and Theory of Architecture course.

It is important to identify the salience of the image or a part of the image to the reader. Writers do this by referring to the specific aspects of the image in their writing that they wish to draw to the reader's attention as part of the argument. In the discipline of architecture, it is also possible to intervene directly in the image through labelling or drawing to highlight a particular point. Lastly, it is as important to reference images as any other idea or textual element. These are referenced both in the caption using author and date, and in more detail in the reference list. (See Appendix B for guidelines on integrating visuals into written assignments).

\section{Writing about predominantly visual texts}

This is probably the most common 'multimodal' text type that students will have to produce in Higher Education. Analyzing visuals spans all levels of study and most academic disciplines. In social anthropology for instance, students could be asked to discuss the relationship between the camera, the filmmaker-producer and the informant in ethnographic filming. In education, students could be asked to critique a 
page or short section in a textbook in a particular discipline. This requires students to look at how the text constructs or positions the learner, and in order to do this, they need to use multimodal tools of analysis. In other words, they need to look at the use of language, as well as the visual design of the text in more depth, including colour, composition, typography, layout.

I would like to explore an example where our Writing Centre provided assistance on a first year Media essay. The essay emanated from a course which addresses image literacy and media writing, one of the biggest first-year Humanities courses. For the past few years, our Writing Centre has conducted a drafting exercise with approximately 500 first-year students in 20 workshops. The rationale for the workshops is to allow students to critically engage with the academic discourse specific to Media by peer editing their first assignment. This assignment involves a social semiotic analysis of a media text, namely an advertisement. The workshops concentrate on how to structure a visual analysis and keep cohesion, emphasizing the importance of having a clear thesis or argument.

In doing this kind of visual analysis for the first time, the students battle on a number of levels. These difficulties are best illustrated by looking at the following introduction and conclusion to a student essay:

My research will elaborate the chosen ad on a semiotical analyzing basis. Semiotics are study of a given sign or text [Stadler J, O' Shaugnessy $M$. (2005)]. I'll focus on the product being interpellated (addressed) and the concept of image. I'll raise a few views on the polysemical meanings that may be suggested and a brief touch of depth on whether the product is suitable in general.

...

The way you present your product, determines the way people interprets them. The visual signifiers, language, presentation and advertising adds up to your credit. In this case,the promoter uses advocacy advertising which means that the product is presented to benefit and gain profit in the end. Being said so, the advert is being marketed very good because the visual signifier has a nice layout on it's appearance. The dark setting with the attention drawing to the colourful gel containers on the left and the catchy, yet controversial slogan. The angle on which the picture of the warthog was shot, shows off the hairstyle that the product is capable of creating. I would say it's pretty good marketing and advertising skills overshadowed by sarcasm and insensitive humour

Despite the obvious difficulty the student has in writing in English, this extract demonstrates difficulties with the visual metalanguage ("polysemical”), a critical 
metalanguage and the language of the discipline ("advocacy advertising” and “interpellated”) and academic discourse in general. Also, the writing vacillates between analysis and evaluation, and between 'reality' and 'representation'. The following sentence evaluates the effectiveness of the advertisement: "I would say it's pretty good marketing and advertising skills overshadowed by sarcasm and insensitive humour". The writer attempts to use a metalanguage of visual analysis ("visual signifier”), but does so only to evaluate the effectiveness of the advertisement, and not to analyze the way in which it has been designed as a representation with a particular purpose: "the advert is being marketed very good because the visual signifier has a nice layout on it's appearance”. The words 'nice' and 'good' clearly point to a highly individualized appraisal of the aesthetics and effectiveness of the advertisement. In looking at "whether the product is suitable in general", the student is evaluating the hair gel product itself and not the representation thereof.

Maintaining a clear argument is especially tricky in a visual analysis which can often feel like a list of unconnected points, arranged according to tools of analysis rather than according to themes. Although different to an analysis of an advertisement, the following consultant's report on a consultation analyzing a computer game, exemplifies some of the difficulties that students have in structuring a textual analysis.

The assignment did require the student to cover certain aspects of the game, but did not require that it be presented in a particular format. For this reason, I focused on logical flow of argument, cohesion and coherence. Some sections lacked context because he omitted key information. These areas where addressed. He also spent too much time on the story line of the game and less on the actually critique. I told him to flesh out the latter part.

In this reflection on the students' writing, the consultant identifies the difficulty of integrating description into a textual analysis. In analyzing any visual text (both where the visual is present and where it is absent), it is important to first describe a particular feature, and then to move on to analyze the implications. However, there is a thin line between too little description ("some sections lacked context because he omitted key information") and too much description ("too much time on the story line of the game”).

The key to a consultation on a text like this would be to get the students to articulate the particular ideologies espoused by the advertisement, and how it draws on and propagates these ideologies in order to sell a product. This would involve questions to 
elicit students' responses. The kinds of questions include: what are your aims with this text? How are you achieving this? Why have you chosen these particular tools? A basic visual metalanguage (Archer 2010) would be required to talk about the text; it would be worth establishing this with the students before in-depth discussion and seeing if this is used consistently in the accompanying written analysis.

A visual analysis requires that key themes are identified. A strong thesis or 'argument' needs to be stated clearly in the introduction and textual details need to be used as evidence of the key themes in order to build up the argument. It is important that there is one main idea per paragraph, indicated by a topic sentence which relates back to one of the central themes of the essay. In order to show the connections between levels of analysis in an essay of this nature, one needs to ask what, how and why questions. The 'what' question provides a description of a phenomenon. The 'how' question provides an explanation on how the desired effect is created using tools of analysis (colour, typography, composition). Finally, the 'why' question addresses the effect of the design features in terms of the original argument or thesis, and also often looks at the larger context.

\section{Implications for Writing Centres}

This paper has explored ways of enabling student access to multimodal texts in Higher Education, specifically focusing on integrating visuals in written text. It also looks at writing about visual texts and issues of 'critical' literacy across modes. The main argument is that texts are never monomodal; reading and writing practices are only one part of what people have to learn in order to be 'literate'. "Monomodality is the result of a certain way of thinking of separate, distinct semiotic resources, abstracted from use, as existing in their own right” (Baldry and Thibault 2006: 19). In light of this, perhaps we need to think more in terms of Communication across the Curriculum (CAC), rather than Writing across the Curriculum (WAC), which has traditionally been the fare of Writing Centres in South Africa. There is a growing trend in the US to refer to 'Communication across the Curriculum' which is in line with current thinking on multimodality (Duffelmeyer and Ellertson 2005, McLeod 2008). CAC is defined as "an expansion of the writing-across-the-curriculum movement that broadens the focus from written communication to all other forms of communication, including oral and visual” (WAC Steering Committee, University of 
Nevada 2008). This widened notion of communication includes the visual design of written assignments, and the redefined nature of texts through new technologies.

Of course, the predominance and importance of a range of multimodal texts depends on the particular context. Writing Centres have come into being to address specific needs on specific campuses, and thus they serve the social context of which they are a part (Murphy 1995). Some courses and tertiary environments may require more multimodal texts than others. As McCleod has pointed out, the changing nature of communication is not always reflected in Higher Education. She refers to a "cultural lag in assignment design” (2008: 2), with the research paper still being one of the most common assignments across the curriculum. She proposes that "we need to find ways of working with faculty in the disciplines to give their students a notion of how professionals in the field actually do their research and write it up, ways that are undergoing tremendous changes” (2008: 2). Given the combination of computer technology and visual communication in our representational landscape, the new production and reception possibilities need to be explicitly engaged. Writing Centres cannot ignore that academic literacies now involve effectively constructing and navigating multiplicity, manipulating and critiquing information and representations in multiple media, and using diverse technologies (print, visual, digital) in composing multimodal texts. This kind of multimodal composing reflects the environment in which students receive and generate text.

\section{Acknowledgements}

The research is based upon work supported by the National Research Foundation (NRF) in South Africa and the University Research Committee at the University of Cape Town. Any opinions, findings or recommendations expressed in this material are those of the author and therefore the NRF does not accept any liability in regard thereto.

\section{References}

Archer, A. 2011. Voice as Design: Exploring academic voice in multimodal texts in Higher Education. N. Pachler and M. Boeck (Eds.) Transformation of Representation. Essays in honour of Gunther Kress. Routledge. Publication pending. 
Archer, A. 2010. Multimodal texts in Higher Education and the implications for writing pedagogy. English in Education. 44 (3): 201 - 213.

Archer, A. 2008. Investigating the impact of Writing Centre intervention on student writing at UCT. South African Journal of Higher Education. 22 (2): 248 - 264.

Archer, A. 2006. A multimodal approach to academic 'literacies': problematizing the visual/verbal divide. Language and Education. 20 (6): 449 - 462.

Baldry. A. and Thibault, P.J. 2006. Multimodal transcription and text analysis. A multimedia toolkit with coursebook. London, Oakville: Equinox.

Barthes R. 1977. Image-Music-Text. London: Fontana.

Buckingham D., Grahame J. and Sefton-Green J. 1995. Making Media - Practical Production in Media Education. London: The English and Media Centre.

Deacon A., Morrison A., Stadler J. 2005. Designing for learning through multimodal production: Film narrative and spectatorship in Director's Cut. International Journal of Education and Development using Information and Communication Technology (IJEDICT). 1 (1): 72 - 89.

Duffelmeyer B. B. and Ellertson A. 2005. Critical Visual Literacy: Multimodal Communication Across the Curriculum. Across the Disciplines. 2 (2). http://wac.colostate.edu/atd/visual/dufflemeyer_ellerston.cfm. [Accessed 10 October 2008]

Huang C. and Archer, A. 2011. Uncovering the multimodal literacy practices in reading manga and the implications for pedagogy. In B. Williams and A. Zenger (eds.) New Media Literacies and Participatory Popular Culture across Borders. Routledge. Publication pending. 
Jewitt C. 2006. Technology, literacy and learning. A multimodal approach. Oxon: Routledge.

Jewitt C. 2009. (ed.) The Routledge Handbook of Multimodal Analysis. Oxon: Oxford University Press.

Kress G. 2000a. Multimodality. In B. Cope and M. Kalantzis. (eds.) Multiliteracies. Literacy Learning and the Design of Social Futures. London and New York: Routledge. 182 - 202.

Kress G. 2000b. Multimodality: Challenges to Thinking About Language. TESOL Quarterly. 34 (2): 2000.

Kress G. 2010. A social semiotic approach to contemporary communication. Oxon, New York: Routledge.

Kress G. and Van Leeuwen T. 2006. Reading Images. The Grammar of Visual Design London: Routledge.

Lea M.R. and Street B. 1998. Student Writing and Faculty Feedback in Higher Education: an Academic Literacies Approach. Studies in Higher Education. 23 (2): $157-165$.

Lillis T. and Scott M. 2007. Defining academic literacies research: issues of epistemology, ideology and strategy. Journal of Applied Linguistics 4 (1): 5 - 32.

Martinec R. and Salway A. 2005. A system for image-text relations in new (and old) media. Visual Communication 4 (3): 337 - 371.

Matthiessen C. 2007. The multimodal page: a systemic functional exploration. In T.D.Royce and W.L.Bowcher (eds) New directions in the analysis of multimodal discourse. New Jersey: Lawrence Erlbaum Associates Inc. Publishers. 1 - 62. 
McLeod S. 2008. The future of WAC. Plenary Address, Ninth International Writing Across the Curriculum Conference, May 2008 (Austin, Texas). Across the Disciplines. 5. http://wac.colostate.edu/atd/articles/mcleod2008.cfm. [Accessed 14 November 2008].

Murphy C. 1995. Writing centers in context: responding to current educational theory. In C. Murphy and J. Law (Eds.) Landmark Essays in Writing Centers. Davis, Hermagoras Press. 117 - 125.

New London Group. 2000. A Pedagogy of Multiliteracies: Designing Social Futures. In B. Cope and M. Kalantzis (eds.) Multiliteracies. Literacy Learning and the Design of Social Futures. London and New York: Routledge. 9 - 38.

Royce T. 2002. Multimodality in the TESOL Classroom: Exploring visual-verbal synergy. TESOL Quarterly. 36 (2): 191 - 205.

Stein P. 2008. Multimodal pedagogies in diverse classrooms: representation, rights and resources. London, New York: Routledge.

Thesen L. 2001. Modes, Literacies and Power: A University Case Study. In Language and Education. 14 (2, 3): 132 - 145.

Unsworth L. 2006. Towards a metalanguage for multiliteracies education: Describing the meaning-making resources of language-image interaction. English Teaching: Practice and Critique. 5 (1): 55 - 76.

WAC Steering Committee, University of Nevada, Las Vegas. 2008. General Education Writing Across the Curriculum Retreat. http://64.233.183.104/search?q=cache:-cZR39tceAJ:writinglinks.unlv.edu/wac/ documents/WAC_Retreat_Session_4_Models.ppt+Communication+Across+the+Curr iculum $+(\mathrm{CAC}) \& \mathrm{hl}=\mathrm{en} \& \mathrm{ct}=\mathrm{clnk} \& \mathrm{~cd}=39$ [Accessed 23 January 2009] 


\section{Appendix A}

\section{Guidelines for Academic Poster Design and Assessment}

\section{Content}

- How well does the introduction establish the context of the research presented?

- Does the conclusion sum up the proposals or argument?

- To what extent is the content supported by in-text referencing to sources?

- Is there a properly presented reference list?

\section{Macro Organization}

- Is the intended audience clear and unambiguous?

- Is the visual uncluttered?

- Is the 'reading path’ clear?

- Are there connections between the sections?

- Do the words and the pictures complement each other, rather than contradict each other?

- Is the choice of a picture or written text appropriate for the message being conveyed (e.g. a cross-section diagram used, rather than a lengthy explanation)?

\section{Micro Organization}

- $\quad$ Are the images chosen directly relevant to your purpose? (for example, mostly written text, graph, table, cross-section diagram, photograph, perspective drawing, realistic drawing, simplified two-dimensional drawing, image from an image bank, flow chart.

- Are the means of representation carefully chosen? For example, black and white; full colour; minimal colour; pencil; pen; thickness of lines.

- Are the colours chosen effective for the purpose, and do they give continuity to the layout?

- Is the text readable from a distance (this includes considering font size, point form, image size)?

- Is the choice of font (size, shape, lightness, boldness) appropriate for the message being conveyed, and are fonts used consistently across the poster? 


\section{Appendix B}

\section{Integrating visuals into written assignments}

1. Are the images near the written analysis thereof?

2. Are the images referred to in the written text, for example "see figure 2 for ..."

3. Are the important aspects of the image referred to in the writing?

4. Do all the images have captions?

5. Do the captions guide the interpretation of the image for the given purpose?

6. Do the captions either specify the interpretation of the image, or complement the image?

7. Is the type of image chosen directly relevant to the purpose? (For instance, a photograph may be better suited to emphasize a building in its context, whereas a more abstract drawing of a plan of a building could emphasize certain structural aspects better than a photograph could.)

8. Are the images referenced in the caption? ('in-text' referencing)

9. Are the sources of the images listed in the reference list? 
Table 1. Types of multimodal texts in academia

\begin{tabular}{|c|c|c|}
\hline $\begin{array}{l}\text { Types of multimodal texts in } \\
\text { Higher Education }\end{array}$ & Function of images & Examples \\
\hline $\begin{array}{l}\text { Predominantly visual texts } \\
\text { (often accompanied by written } \\
\text { reflection) }\end{array}$ & $\begin{array}{l}\text { The content and certain } \\
\text { rhetorical functions are realized } \\
\text { in the visual mode }\end{array}$ & $\begin{array}{l}\text { Posters, storyboards, 'culture } \\
\text { jamming' (usually of } \\
\text { advertisements), technical } \\
\text { drawings, photo essays, } \\
\text { financial reports and texts often } \\
\text { realized through 'new' media } \\
\text { such as power point, websites, } \\
\text { videos or DVDs. }\end{array}$ \\
\hline Written texts that use images & $\begin{array}{l}\text { Images are used in conjunction } \\
\text { with writing to: } \\
\text { - } \quad \text { provide context } \\
\text { - } \quad \text { illustrate a point } \\
\text { - } \quad \text { make an argument } \\
\text { (often numerical) } \\
\text { - } \quad \text { furnish evidence } \\
\text { - } \quad \text { organize data (as in } \\
\\
\text { flowcharts and tables) }\end{array}$ & $\begin{array}{l}\text { Essays and reports from all } \\
\text { disciplines use images, to } \\
\text { greater or lesser degrees. This } \\
\text { category also includes texts with } \\
\text { numerical data displayed in } \\
\text { charts and tables, such as } \\
\text { environmental impact } \\
\text { assessments, cost benefit } \\
\text { analyses, investigative reports, } \\
\text { and so on. }\end{array}$ \\
\hline $\begin{array}{l}\text { Written texts that analyze and } \\
\text { discuss visuals }\end{array}$ & $\begin{array}{l}\text { Image acts as the catalyst or } \\
\text { primary text for the written } \\
\text { analysis. At times the image is } \\
\text { included in the text, but } \\
\text { sometimes it is omitted, such as } \\
\text { in the analysis of a film or } \\
\text { ethnographic data. In these } \\
\text { cases, it is described in the } \\
\text { written mode. }\end{array}$ & $\begin{array}{l}\text { Analyses of an advertisement, } \\
\text { film, poster, image, building, } \\
\text { computer game. This usually } \\
\text { takes the form of an academic } \\
\text { essay. This category also } \\
\text { includes the analysis of visual } \\
\text { data such as video clips when } \\
\text { using visual methodologies in } \\
\text { primary research. }\end{array}$ \\
\hline
\end{tabular}


Table 2 Storyboard for short film entitled 'Dolls and Diamonds' produced by a first

\section{year Film student}

\begin{tabular}{|c|c|c|c|c|}
\hline & Shot Name & Duration & Shot Description & Script: 'Dolls and Diamonds' \\
\hline 1 & Dick & $17 ”$ & $\begin{array}{l}\text { Arrival from Dick's perspective. } \\
\text { He knocks on door, she says 'I've } \\
\text { been expecting you, detective'. She } \\
\text { invites him in. }\end{array}$ & $\begin{array}{l}\text { [Dick v/o] This was my luck } \\
\text { day. } \\
\text { [Femme] I've been expecting } \\
\text { you, detective. }\end{array}$ \\
\hline 2 & A: & $4 ”$ & $\begin{array}{l}\text { Long Shot (LS) Establishing shot. } \\
\text { Dick and Femme sit down on } \\
\text { couch. }\end{array}$ & \\
\hline 3 & $\begin{array}{l}\text { E: MCU O/shoulder, } \\
\text { Dick dialogue }\end{array}$ & $3 ”$ & $\begin{array}{l}\text { Medium close up (MCU) of Dick } \\
\text { saying 'What happened in Room } \\
\text { 237?” (shot over her shoulder) }\end{array}$ & $\begin{array}{l}\text { [Dick] What happened in } \\
\text { Room 237? }\end{array}$ \\
\hline 4 & $\begin{array}{l}\text { D: MCU O/shoulder, } \\
\text { Femme dialogue }\end{array}$ & $3 ”$ & $\begin{array}{l}\text { MCU of Femme saying 'what do } \\
\text { you think?' (shot over his } \\
\text { shoulder) }\end{array}$ & [Femme] What do you think? \\
\hline 5 & T: Dick’s Flashback & $14 ”$ & $\begin{array}{l}\text { Zoom in from VCU to ECU Dick's } \\
\text { eyes, dissolve to his handheld point } \\
\text { of view (pov) of her leaving room } \\
\text { 237, dissolve back to ECU his } \\
\text { eyes. }\end{array}$ & $\begin{array}{l}\text { [Dick v/o] She was playing } \\
\text { with me. Its the same story she } \\
\text { gave the cops about finding } \\
\text { the stiff in Room } 237 \text {. I wasn't } \\
\text { buying it. Crooked or not, Bill } \\
\text { Young was the best poker } \\
\text { player I knew... }\end{array}$ \\
\hline 6 & Z: Femm & $7 ”$ & $\begin{array}{l}\text { CU of Femme glancing down. Cut } \\
\text { to MCU from over Dick's shoulder } \\
\text { as she covers her legs with her } \\
\text { gown. }\end{array}$ & $\begin{array}{l}\text { [Dick v/o] ...but when a pretty } \\
\text { lady is found with a big } \\
\text { shiner, the pigs always fold. } \\
\text { The bruises were gone, but } \\
\text { this doll's performance was a } \\
\text { class act. }\end{array}$ \\
\hline 7 & X: Pop cork & $4 ”$ & $\begin{array}{l}\text { Close up (CU) high angle of hands } \\
\text { opening champagne. The cork pops } \\
\text { and we hear the fizz. }\end{array}$ & $\begin{array}{l}\text { [Dick v/o] What ever went } \\
\text { down, they were celebrating } \\
\text { something. }\end{array}$ \\
\hline 8 & Q: Femme lights & 8” & $\begin{array}{l}\text { Starts with MCU Dick's pov, cuts } \\
\text { to Femme’s pov of cig, then } \\
\text { objective Extreme Close Up (ECU) } \\
\text { of cig+ fingers, then back to MCU } \\
\text { from Dick's pov. }\end{array}$ & $\begin{array}{l}\text { [Dick v/o] With two major } \\
\text { jewellery heists in the the last } \\
\text { month, ol' Tennyson had been } \\
\text { busy. The cops couldn't pin } \\
\text { him, but my gut told me that } \\
\text { him and his dame pulled it off. }\end{array}$ \\
\hline 9 & W: Shattered glass & $4 ”$ & $\begin{array}{l}\text { Anonymous man drops champagne } \\
\text { glasses. Cut to high angle of } \\
\text { shattered glass on floor. }\end{array}$ & $\begin{array}{l}\text { [Dick v/o] ...but she got } \\
\text { greedy, and poor Tennyson... }\end{array}$ \\
\hline
\end{tabular}




\begin{tabular}{|l|l|r|l|l|}
\hline 1 & Y: Gun & 3” & $\begin{array}{l}\text { Hand held low level gun on floor, } \\
\text { canted frame. }\end{array}$ & $\begin{array}{l}\text { [Dick v/o] ...paid his price in } \\
\text { blood. }\end{array}$ \\
\hline 1 & $\begin{array}{l}\text { P: CU Femme glance } \\
\text { down }\end{array}$ & 3” & $\begin{array}{l}\text { Straight angle as she meets his } \\
\text { eyes, then glances down }\end{array}$ & \\
\hline
\end{tabular}


Figure 1: Extract from a first year architecture essay

As the confidence grew for the establishment intended only for passing ships, Dutch Governor Simon van der Stel was sent with the purpose of further development of the area in terms of cultural and commercial prosperity. This action was of immense importance concerning the development of the architecture in Cape Town. Van der Stel built Groot Constantia, a superb example of the typical Cape Dutch homestead. A definitive South - African architectural language was born (fig.2).

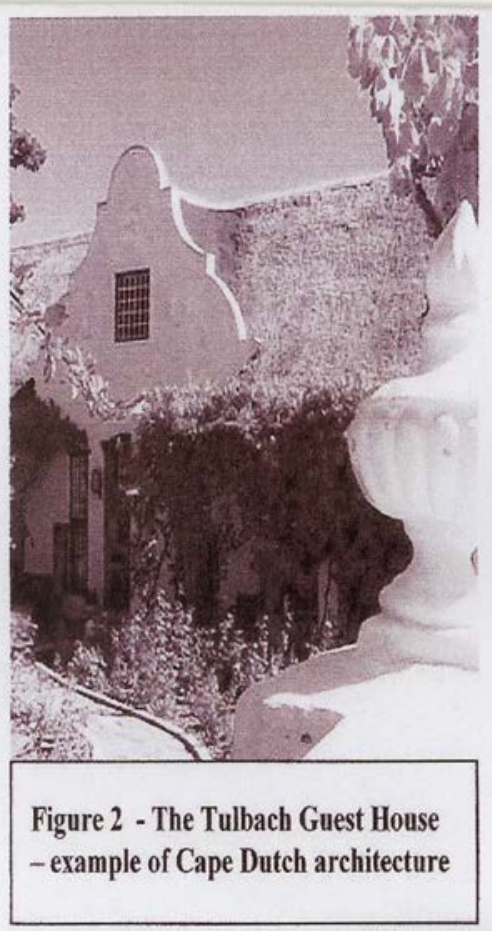

